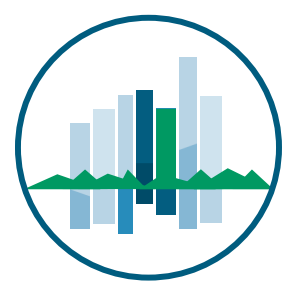

True Smart and Green City?

8th Conference of the

International Forum on Urbanism
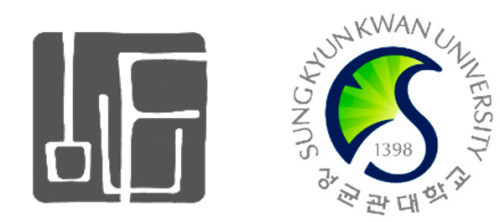

Conference Proceedings Paper

\title{
Differing Government Discourses on Korean U-City and Smart City: Cases of Songdo, Sejong City and Seoul
}

\author{
Ji-in Chang ${ }^{1, *}$, Yea Sung Kim ${ }^{2}$ and Aei Jung Song ${ }^{3}$
}

1 Graduate School of Smart City Science Management, Hongik University, 2639 Sejong-ro, Jochiwon, Sejong City 339-701, Korea

2 Seoul Institute, Nambusunhwan-ro 340-gil Seocho-gu, Seoul 137-071, Korea

3 Graduate School of Environmental Studies, Seoul National University, 1 Gwanak-ro, Gwanak-gu, Seoul 151-742, Korea

* Author to whom correspondence should be addressed; Tel.: +82-10-6277-0973; Fax: +82-44-8602618; E-mail: twomay_jiin@hongik.ac.kr

\begin{abstract}
As a self-proclaimed 'IT Power Nation', Korea has incorporated information technology at the core of its vision for future development. Already 'ubiquitous eco-cities', most notably Songdo and Sejong City, have been master-planned by the Korean national government and are well under construction as sustainable smart cities of the future. These ucities are defined as intelligent eco-friendly cities using advanced technologies to enhance the citizens' quality of life and city competitiveness. At the municipal level, Seoul, Korea's capital of more than 600 years of history, has adopted 'Smart Seoul' as a slogan since 2011. Interestingly, however, Seoul's mayor emphasizes communication and sharing as major aspects characterizing a smart city. In view of these different approaches, it is pertinent to question the definitions for these u-cities/smart cities and to examine the extent of their commonality as shown in relevant government initiatives and statements. The aim of this paper is to shed light on what is meant to be a smart and green city by critically examining the underlying premises of varying government perspectives. Using Songdo, Sejong City and Seoul as three case studies, the paper focuses, firstly, on the nexus of u-city and smart city definitions, and, secondly highlights the differing government discourses imbedded in their social, economic and environmental policies. Ultimately, the paper calls for a more integrated understanding and vision in government discourses regarding the smart city.
\end{abstract}

Keywords: smart city; u-city; eco-city; Songdo, Sejong City, Seoul 